\title{
Plasmonic Effect of Ag Nanoparticles on Polymethine Dyes Sensitized Titanium Dioxide
}

\author{
Niyazbek Ibrayev,,${ }^{1, *}$ Gulden Omarova, ${ }^{1}$ Evgeniya Seliverstova, ${ }^{1}$ Alexander Ishchenko ${ }^{2}$ and Nurxat Nuraje ${ }^{3, *}$
}

\begin{abstract}
The effect of core@shell nanostructure of $\mathrm{Ag@OTiO} 2$ on the spectral-luminescence properties of polymethine dye (PD) functionalized with sulfonate group and its photovoltaic properties in the PD dye-sensitized solar cell were investigated. Quenching in the fluorescence intensity of PDs molecule by almost 3 times was observed for the dye-absorbed titanium dioxide porous film. Furthermore, the decreasing effect in fluorescence lifetime was found to be significant for the PD

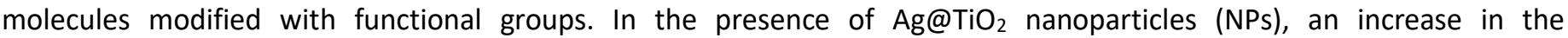
luminescence intensity of PD by $60-90 \%$ was observed. A mechanism of plasmon nanoparticles' effect on the decay of the excited states of dye molecules was proposed. The efficiency of PD-sensitized solar cells was increased by 1.2 times for PD 1 and 2.0 times for PD 2. The enhancement in the efficiency is result from the growth in the spectral sensitivity of solar cell in the region of $400-450$ and $600-700 \mathrm{~nm}$ and a change in the charge-transport parameters of $\mathrm{TiO}_{2}$ films. This increase was supported by a decrease in the resistance at the semiconductor-dye interface by 8.2 times for PD 1 and 22.4 times for PD 2 that leads to the growth in the part of photoelectrons reaching the counter electrode in solar cell with plasmon NPs.
\end{abstract}

Keywords: Dye-sensitized solar cell; Polymethine dye; Plasmon; Core-shell structure; Optical properties.

Received: 2 December 2020; Accepted: 15 January 2020.

Article type: Research article.

\section{Introduction}

Dye-sensitized solar cell (DSSC) has been developed more than 20 years ago and still interest of specialists. ${ }^{[1]}$ Its popularity is ascribed to low production cost, stability, transparency and flexibility compared to other photovoltaic units.

In the DSSC, the function of metal complex dyes, adsorbed on the semiconductor layer, is to harness solar energy. For example, Ru-polypyridine dyes are the major dyes used in the Grätzel cell since they possess high absorption characteristics and chemical stability. The efficiency of DSSCs varies in the range of $7-12 \%$ in terms of the dyes applied. ${ }^{[1 b, 1 c]}$ Porphyrin complexes are also

\footnotetext{
1 Institute of Molecular Nanophotonics, Buketov Karaganda University, 100028 Karaganda, Kazakhstan.

${ }^{2}$ Institute of Organic Chemistry, NAS of Ukraine, 02660 Kyiv, Ukraine.

${ }^{3}$ Department of Chemical \& Materials Engineering, School of Engineering and Digital Sciences, Nazarbayev University, 010000 Nur-Sultan, Kazakhstan.

*Email: niazibrayev@mail.ru (N. Ibrayev),nurxat.nuraje@nu.edu.kz (N. Nuraje)
}

actively used and their maximum efficiency of cells can reach $13 \%$, while DSSCs consisted of them demonstrate an efficiency of about $3-5 \% .{ }^{[2]}$

Despite all the advantages of metal complexes, their synthesis is a very time-consuming and expensive. Metal-free organic donor-acceptor dyes can be prepared with relatively low costs and well-established synthesis methods. The main advantage of dyes without metal ions is their tunable absorption and electrochemical properties, which can be achieved with an appropriate dye synthesis strategy.

Today, progress in the utilization of non-metallic dyes for the DSSC has been observed. For instance, Ref. ${ }^{[3]}$ reported $14.3 \%$ of solar cell efficiency for the DSSC co-sensitized with two functionalized carbazole oligothiophenes. As a result of using of two dyes, the spectral sensitivity of the DSSC in the visible region of the spectrum was increased. The authors of Ref. ${ }^{[4]}$ have achieved a cell efficiency of $17.3 \%$ as chlorine-substituted graphdiyne applied in organic solar cells. A similar approach was also implemented in Refs., ${ }^{[5]}$ where the Förster resonance energy transfer was used to improve light harvesting, as well as to increase the efficiency of photogeneration of charge carriers.

Metal-free dyes are a good alternative to metal complexes, because they are cheap and easy to be synthesized or to be 
modified. For example, since they have high extinction coefficients and tunable absorption spectra in the entire visible and near-infrared regions, ${ }^{[6]}$ polymethine dyes (PDs) demonstrated potential applications for photovoltaics. ${ }^{[7]}$ The solar cell efficiency reported for these dyes varies from 0.5 to $3 \% .{ }^{[8]}$ As it was reported in Refs., ${ }^{[8,9]}$ about $\sim 7 \%$ increase in efficiency can be achieved for PDs molecules modified with anchor groups, such as, sulfonate, hydroxy- and carboxyl groups.

To increase the efficiency of solar cells, the strategies of surface plasmonic enhancement by metal nanoparticles $(\mathrm{NPs})^{[10]}$ and enhancement of electrophysical properties of a semiconductor layer ${ }^{[11]}$ have been applied. Furthermore, metal NPs can be placed inside and outside the working electrode to increase the light collection of solar cells, via surface plasmonic and the light scattering effect of metal NPs. ${ }^{[12]}$ In addition, the localized plasmon resonance (LPR) of metal nanoparticles improves the spectral sensitivity of solar cells, and also affects the efficiency of injection and transport of charge carriers inside the semiconductor. In particular, the introduction of plasmonic NPs into $\mathrm{TiO}_{2}$ films results in the growth in the mobility of charge carriers in the semiconductor. ${ }^{[12]}$ The negative effects of plasmonic NPs on the working components of solar cells can be neglected.

At the same time, the LPR of metal NPs also can weaken the luminescence of dye molecules, depending on the conditions. ${ }^{[10,13]}$ For example, fluorescence quenching is usually observed as the LPR band significantly overlaps with the luminescence spectra of the dye. ${ }^{[10,14]}$ To obtain metal-enhanced luminescence a series of requirements in the "metal NPs-dye" system including spectral overlap among the spatial arrangement of the dipoles of dye and NP in the excitation region, and the absence of charge transfer between dye and plasmon NPs.

The aim of this work is to investigate the effect of silver NPs on the spectral-luminescent and photovoltaic properties of polymethine dyes in the DSSC. For this purpose, we selected PD 1 and PD 2 dyes $^{[15]}$ of the same structural type without and with functional sulfonate groups.

\section{Experimental part}

The structural formulas of the studied dyes are shown below. PD 1 is a cationic PD and does not have functional groups. PD 2 contains negatively charged (anchor) sulfonate groups.
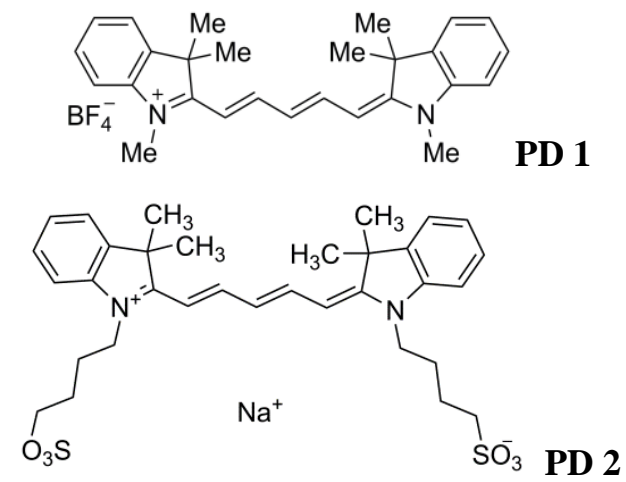

To measure the spectral-luminescent properties of studied polymethines $\mathrm{TiO}_{2}$ films with and without core@shell nanostructures, a doctor-blading method was applied to construct the above films onto quartz substrates. Then, PDs were sorbed from an ethanol solution with a concentration of $10^{-4} \mathrm{~mol} / \mathrm{L}$ onto the surface of porous $\mathrm{TiO}_{2}$. The concentration of $\mathrm{Ag} @ \mathrm{TiO}_{2} \mathrm{NPs}$ was equal to $0,0.5,1$, and 2 $\mathrm{wt} \%$. A detailed synthesis technique for these nanostructures and their physicochemical properties is described in Ref.[11]

Dynamic light scattering method (Zetasizer 90S, Malvern) was used to estimate the sizes of Ag NPs. The analysis has showed (Fig. 1) that the average radii of synthesized Ag NPs was equal to $20 \pm 5 \mathrm{~nm}$, and the maximum absorption in ethanol was at $405 \mathrm{~nm}$. After the addition of titanium tetraisopropoxide (TTIP, Sigma Aldrich) to the silver NPs solution, a $2-7.5 \mathrm{~nm}$ thick shell was formed which is also seen from the TEM images and EDA analysis (JEM-2100F, Jeol, $200 \mathrm{kV}$ ). Peaks at 1,8 , and $9 \mathrm{keV}$ are attributed to the $\mathrm{Cu}(0.93 \mathrm{keV} \mathrm{L} \alpha, 8.04 \mathrm{keV} \mathrm{K} \alpha$ and $8.91 \mathrm{keV} \mathrm{K} \beta) . \mathrm{Cu}$ appears in the spectra because dispersions of core@shell NPs in ethanol were sonicated for 20 minutes and then they were deposited onto copper grid, pretreated with polymer, and left to dry completely.

The UV-vis spectrum of the studied solutions and films were obtained by the Cary-300 spectrophotometer (Agilent). Fluorescence spectra were measured on the Cary Eclipse (Agilent) spectrofluorimeter. The fluorescence decay kinetics of dyes were measured by the time-correlated single photon counting system (TCSPC) using the TCSPC system (Becker\&Hickl, Germany) with laser excitation at $\lambda_{\mathrm{ex}}=488$ and 532 for PD 1 and 2, respectively. Fluorescence lifetimes were estimated with the help of SPC Image software (Becker\&Hickl). All measurements were performed at room temperature.

The luminescence decay rate can be described by the formula:

$$
I(t)=\sum_{i=1}^{n} \alpha_{i} \exp \left(-t / \tau_{i}\right)
$$

where $\tau_{\mathrm{i}}$ is the decay time, $\alpha_{\mathrm{i}}$ is the amplitude (contribution fraction) of the $\mathrm{i}$-th component $\left(\sum_{i} \alpha_{i}=1.0\right)$.

FTO glasses were used to assemble solar cell. A $\mathrm{TiO}_{2}$ blocking layer was deposited on the FTO surface according to the procedure described in Ref. ${ }^{[1 c, 5 a]} \mathrm{The}^{\mathrm{TiO}}{ }_{2}$ porous film was deposited upon blocking layer by the doctor-blade method. The SEM has shown that the thickness of the obtained films was equal to $10-12 \mu \mathrm{m}$. Solar cells were sensitized by the studied PDs from ethanol solutions with a concentration of $5 \cdot 10^{-4} \mathrm{~mol} / \mathrm{L}$. Next, Pt electrodes were separately prepared on the FTO surface from an ethanol solution of $\mathrm{H}_{2} \mathrm{PtCl}_{6}$ (Sigma Aldrich). Fabrication of all cells were followed the standard technique introduced in Ref. ${ }^{[1 b]}$ 


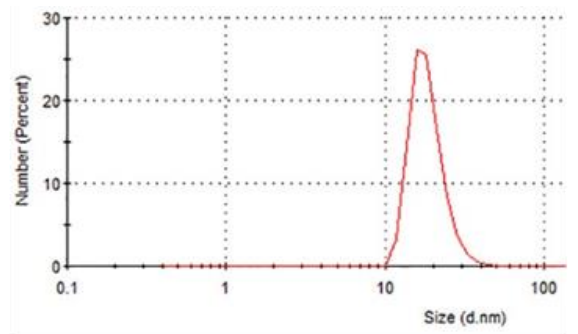

a

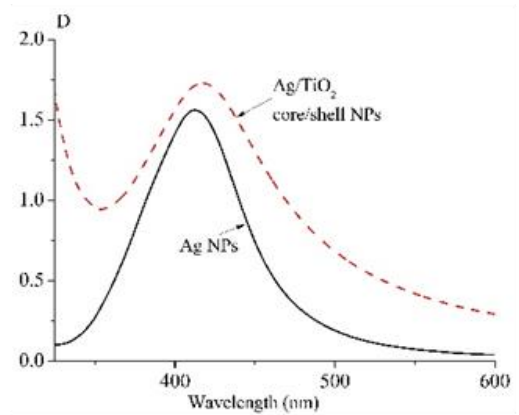

C

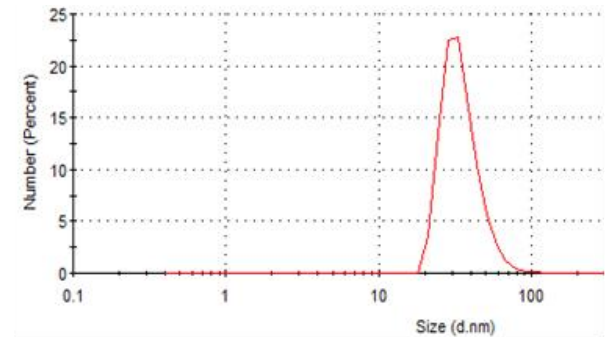

b

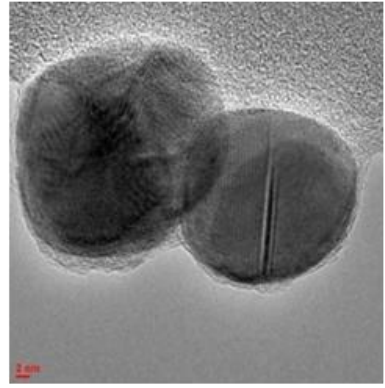

d

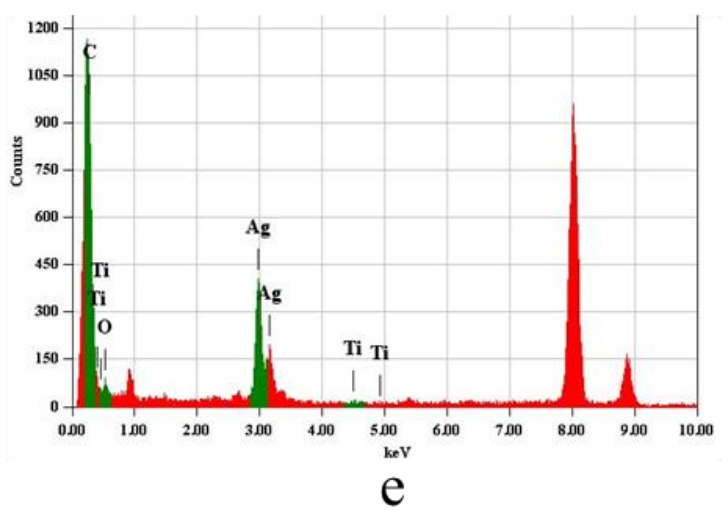

Fig. 1 Size distribution (a, b), absorption spectra (c), TEM image (d) and EDA analysis (e) of Ag NPs before (a, c) and after (b-e) synthesis of $\mathrm{TiO}_{2}$ shell.

The Cell Tester Model \# CT50AAA (Photo Emission Tech., Inc., United States) was used to measure the photovoltaic parameters of prepared solar cells with plasmon nanostructures. The samples were illuminated with the 1.5 AM Xe lamp. From the obtained data of the open circuit voltage, short circuit current, the fill factor, the value of the efficiency of the cells was determined.

The efficiency of $\mathrm{TiO}_{2}$ film sensitized by PDs in the presence of core@shell NPs was studied from the curves of dependence of efficiency of solar cells via wavelength of irradiation. The necessary wavelengths region was divided with the using of optical cut-off filters placed after Xe lamp. The intensity of light for each wavelength region was normalized for maximum transmittance.

$\mathrm{Z}$ - 500PRO impedance meter (Elins) was used to study the kinetics of transport and recombination of charge carriers for the samples under illumination of a Xe lamp. Data analysis was performed using the EIS-analyzer software, while the electric transport properties of the films were calculated according to the methodology of works ${ }^{[16]}: \tau_{\text {eff. }}-$ effective electron lifetime, $R_{w}$ - electron transport resistance in a titanium dioxide film, $R_{k}$ - charge transfer resistance ( $\left.R_{k}=R_{w \max }-R_{w \min }\right)$, associated with electron recombination.

\section{Results and its discussions}

In order to elucidate the effect of functional groups on the spectral and luminescent characteristics of PDs, their absorption and fluorescence spectra were measured in ethanol solutions (Fig. 2a).

As the measurements showed, the absorption bands of PD 1 and 2 are located in almost the same spectral range and have a similar shape with a vibrational maximum at the short-wavelength edge. ${ }^{[6 a]}$ This is a consequence of the fact that they have almost the same chromophore.

The short-wavelength maximum $\left({ }^{a} \lambda_{2} \max \right)$ is at $600-605$ $\mathrm{nm}$ exhibits as a shoulder on the dye absorption curve. The half-width of the spectra $\Delta \lambda_{1 / 2}$ and the extinction coefficients $\varepsilon$ of the studied PDs are close in value. 


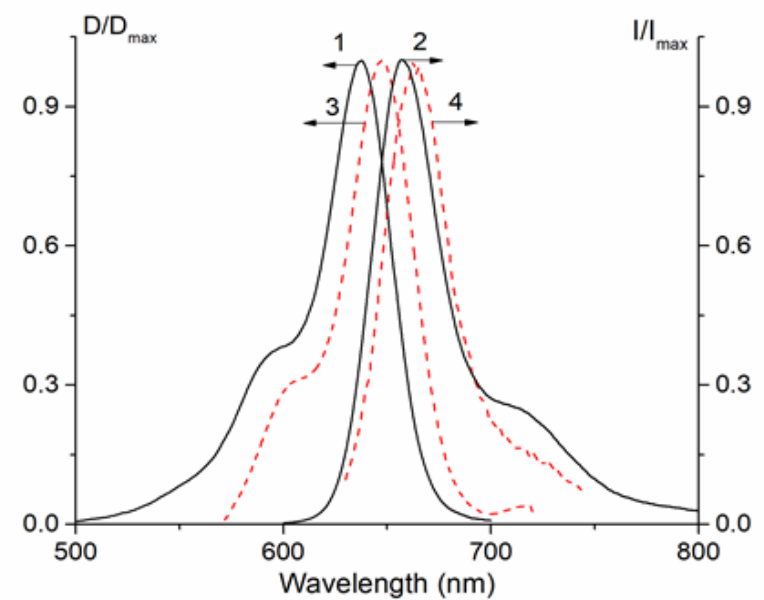

(a)

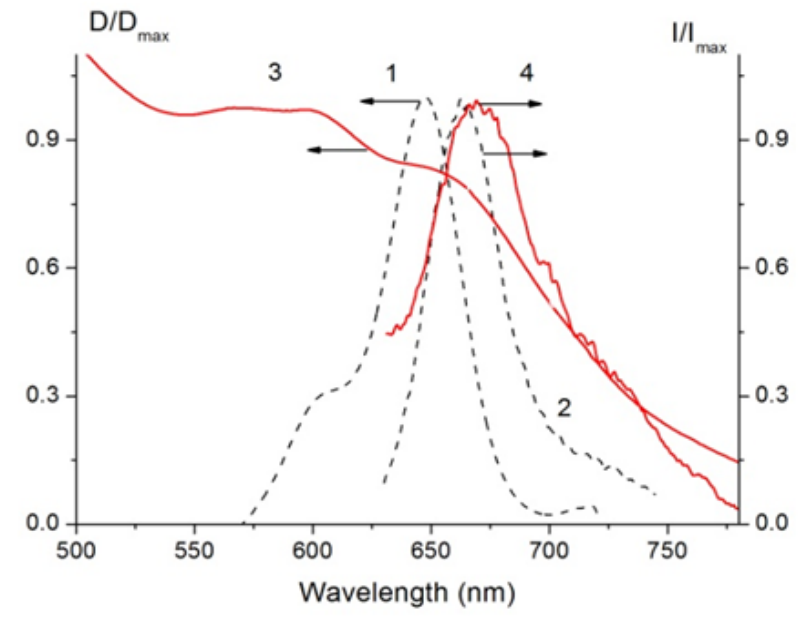

(b)

Fig. 2 (a) Normalized absorption $(1,3)$ and fluorescence spectra $(2,4)$ of dyes: $1-1,2 ; 2-3$, 4. (b) Normalized absorption (1, 3) and fluorescence $(2,4)$ spectra of dye 2 in ethanol $(1,2)$ and $\mathrm{TiO}_{2}(3,4)$.

Table 1 Spectral parameters* of PDs in solutions at $\mathrm{C}=10^{-4} \mathrm{~mol} / \mathrm{L}$.

\begin{tabular}{cccccccc}
\hline Dye & $a \lambda_{1 \max }, \mathrm{nm}$ & ${ }^{a} \lambda_{2 \max }, \mathrm{nm}$ & $\Delta \lambda^{a}{ }_{1 / 2}, \mathrm{~nm}$ & $\begin{array}{c}\varepsilon \cdot 10^{5}, \\
\mathrm{~L} / \mathrm{mol} \mathrm{cm}\end{array}$ & $f \lambda_{1 \max }, \mathrm{nm}$ & $f \lambda_{2 \max }, \mathrm{nm}$ & $\Delta \lambda^{f}{ }_{1 / 2}, \mathrm{~nm}$ \\
\hline PD 1 & 640 & 600 & 45 & 2.13 & 655 & 715 & 31 \\
PD 2 & 646 & 605 & 46 & 2.30 & 663 & 730 & 32 \\
\hline
\end{tabular}

$*{ }^{a} \lambda_{1 \text { max }}-$ maximum of absorption spectra, ${ }^{a} \lambda_{2 \text { max }}$ - maximum of shoulder in absorption spectra, ${ }^{f} \lambda_{1 \max }-$ maximum of fluorescence spectra, ${ }^{f} \lambda_{2}$ max - maximum of shoulder in fluorescence spectra, $\Delta \lambda_{1 / 2}$ - half-width of absorption or fluorescence spectra, $\varepsilon-$ extinction coefficients.

On the porous surface of $\mathrm{TiO}_{2}$ films, a bathochromic shift electron transfer is carried out upon irradiation of PDs on the of the absorption and fluorescence spectra of the studied $\mathrm{PDs} \quad \mathrm{TiO}_{2}$ surface. ${ }^{[17]}$

was observed (Table 2). The shift of the absorption spectrum It should be noted that for the PD 2 dye with sulfonate is greater for functionalized dyes and the intensity of the groups, $\tau_{f l}$ on the surface of the $\mathrm{TiO}_{2}$ film was decreased 3 short-wavelength maximum of the absorption spectra of dyes times in comparison with $\tau_{f l}$ in the solution. Whereas the life onto the $\mathrm{TiO}_{2}$ surface is increased significantly (Fig. 2b).

The fluorescence spectra of dyes in the adsorbed film are also bathochromically shifted relative to the emission bands of PDs in solution. In this case, the fluorescence lifetime $\left(\tau_{f l}\right)$ of the dyes is decreased, which indicates that photoinduced time for PD 1 was decreased by 2.75 times under the same conditions. This can be explained as result of the increased charge transfer process from the dye to the semiconductor due to better contact of functionalized molecules with titanium dioxide nanoparticles. ${ }^{[9 b]}$

Table 2 Spectral-luminescent properties* of PDs on the surface of porous $\mathrm{TiO}_{2}$ films.

\begin{tabular}{|c|c|c|c|c|c|c|}
\hline Sample, wt $\%$ & ${ }^{a} \lambda_{\max }, \mathrm{nm}$ & $D$ & ${ }^{f} \lambda_{\max }, \mathrm{nm}$ & $I$, a.u. & $I / I_{0}$ & $\tau_{f l}, \mathrm{~ns}$ \\
\hline \multicolumn{7}{|l|}{ PD 1} \\
\hline Solution & 640 & - & 655 & - & - & 1.10 \\
\hline $\mathrm{TiO}_{2}$ & 648 & 0.67 & 663 & 53 & - & 0.40 \\
\hline $\mathrm{Ag} @ \mathrm{TiO}_{2} 0.5 \%$ & 648 & 0.69 & 660 & 84 & 1.59 & 0.40 \\
\hline $\mathrm{Ag} @ \mathrm{TiO}_{2} 1.0 \%$ & 648 & 0.71 & 657 & 75 & 1.41 & 0.50 \\
\hline $\mathrm{Ag} @ \mathrm{TiO}_{2} 2.0 \%$ & 648 & 0.9 & 663 & 54 & 1.02 & 0.63 \\
\hline \multicolumn{7}{|l|}{ PD 2} \\
\hline Solution & 646 & - & 663 & - & - & 1.90 \\
\hline $\mathrm{TiO}_{2}$ & 655 & 1.03 & 668 & 23 & - & 0.62 \\
\hline $\mathrm{Ag} @ \mathrm{TiO}_{2} 0.5 \%$ & 655 & 1.09 & 670 & 58 & 2.5 & 0.74 \\
\hline $\mathrm{Ag} @ \mathrm{TiO}_{2} 1.0 \%$ & 655 & 1.04 & 671 & 42 & 1.82 & 0.70 \\
\hline $\mathrm{Ag} @ \mathrm{TiO}_{2} 2.0 \%$ & 655 & 1.00 & 674 & 30 & 1.30 & 0.70 \\
\hline
\end{tabular}

$* a \lambda_{\max }-$ maximum in absorption spectra, ${ }^{f} \lambda_{\max }-$ maximum in fluorescnce spectra, $D$ - optical density in ${ }^{a} \lambda_{\max }, I-$ fluorescence intensity, $\tau_{f l}$ - fluorescence lifetime. 
As plasmon $\mathrm{Ag}$ NPs were added to the $\mathrm{TiO}_{2}$ film, an enhanced fluorescence of PDs was registered. Moreover, the maximum increase in intensity was recorded at a concentration of $\mathrm{Ag} @ \mathrm{TiO}_{2} \mathrm{NPs}$, equal to $0.5 \mathrm{wt} \%$. The plasmon-enhancement of the polymethine's fluorescence, $I / I_{0}$, is greater for functionalized PD 2. In particular, the maximum values of $I / I_{0}$ were equal to 1.6 and 1.9 , for PD 1 and 2, respectively. Meanwhile there were no noticeable changes in optical density (3-5\%) of dyes.

This increase in the dyes fluorescence intensity could be the result of the growth of the radiative transition between excited and ground state of dye molecules. As the optical density of the molecules was almost unchanged, the excitation rate of molecules remains almost the same. However, at the growth in the radiative decay rate of $S_{1}$-state of dye, usually the decreasing in the fluorescence lifetime is observed. As seen from the Table $2, \tau_{f l}$ of PDs show the increasing upon the growth of $\mathrm{Ag} @ \mathrm{TiO}_{2} \mathrm{NPs}$ concentration in the films.

The observed trend may be the result of an increase in the efficiency of fluorescence with a simultaneous weakening of the nonradiative deactivation of the $\mathrm{S}_{1}$ state of the PDs molecules. ${ }^{[13 a, 18]}$ The second case for the increase in the dye fluorescence lifetime is the reverse energy transfer from $\mathrm{Ag} @ \mathrm{TiO}_{2} \mathrm{NPs}$ to the dye molecule, as was shown in the work of Ref. ${ }^{[14]}$ The authors showed that in the case of the close arrangement of the dye and plasmon NPs, along with the quenching of the dye fluorescence by energy transfer to $\mathrm{Ag}$ NPs, a reverse process is also possible, which is delayed in time and leads to an increase in the dye fluorescence lifetime.

For PDs, the weakening in nonradiative deactivation of the $S_{1}$ state can occur due to a decrease in the main channel of deactivation of the excited state - photoisomerization around the bonds of the polymethine chain. ${ }^{[19]}$ Its decrease on the surface of $\mathrm{TiO}_{2}$ films is logical due to an increase in the structural rigidity of the PDs molecule on its surface. Since

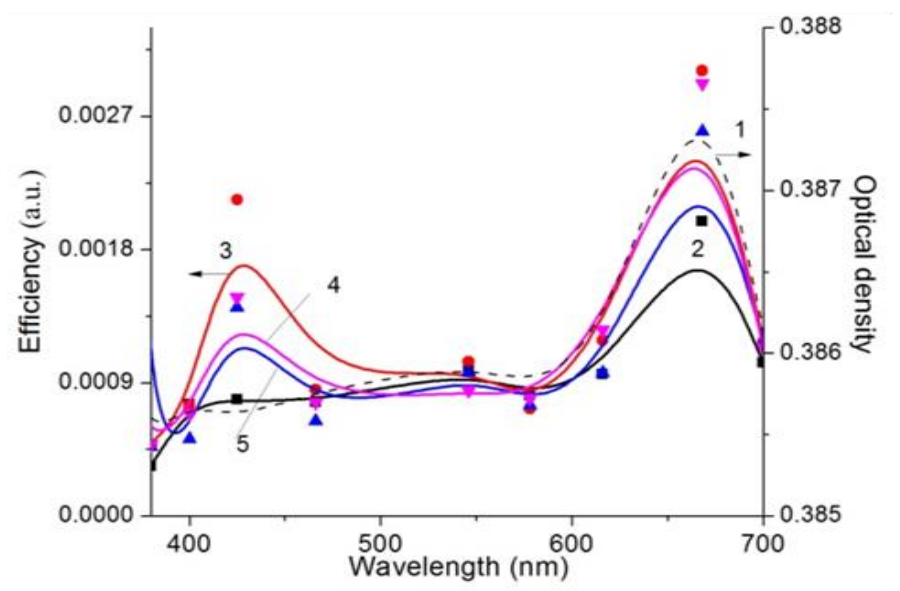

the rigidity of functionalized PD 2 increases more than that of PD 1, it can be expected that the nonradiative constant decreases more strongly for the first dye than for the second. Hence, $\tau_{f l}$ for PD 2 should be increased more than for PD 1. However, we have the opposite picture (Table 2). In particular, in the presence of Ag NPs, $\tau_{f l}$ increased by 1.6 times and 1.15 times for PD 1 and 2 respectively. It proves the second mechanism.

It is possible that the process of reverse energy transfer from $\mathrm{Ag} @ \mathrm{TiO}_{2} \mathrm{NPs}$ to PD 1 is more efficient due to the absence of bulk sulfonate groups in it, due to which PD 1 can approach the plasmon NPs at a closer distance. The effect of an increase in the fluorescence lifetime of merocyanine dye molecules near the surface of Ag NPs was also observed in Ref. ${ }^{[20]}$

The photovoltaic parameters of polymethine sensitized solar cells are presented in Table 3, where: $J_{\mathrm{sc}}-$ short circuit current density values, $V_{o c}-$ open circuit voltage, $F F$ - fill factor, $\eta$ - cell efficiency.

Solar cell, sensitized with PD 1, has a low efficiency, which is due to the low value of the short circuit current of the cell. However, as $\mathrm{Ag} @ \mathrm{TiO}_{2} \mathrm{NPs}$ were added to the film, there was 2 times increase in the efficiency of the cell. As can be seen from the table, this is primarily due to an increase in the values of $J_{s c}$. For solar cells sensitized with PD 2 has higher cell efficiency.

The addition of $0.5-1 \mathrm{wt} \%$ of $\mathrm{Ag} @ \mathrm{TiO}_{2} \mathrm{NPs}$ to the $\mathrm{TiO}_{2}$ film leads to an increase in solar cell efficiency by $15-20 \%$ for functionalized dyes, which is related to the increase of $J_{\mathrm{sc}}$ value. An increase in the concentration of $\mathrm{Ag} @ \mathrm{TiO}_{2} \mathrm{NPs}_{\text {h }}$ a smaller effect on the efficiency of photoconversion of incident light by a solar cell.

The change in $J_{s c}$ directly indicates an increase in the number of charge carriers in the solar cell. The growth in charge carriers may be due to the expansion of the spectral sensitivity of solar cells in the presence of $\mathrm{Ag} @ \mathrm{TiO}_{2}$ nanostructures (Fig. 3).

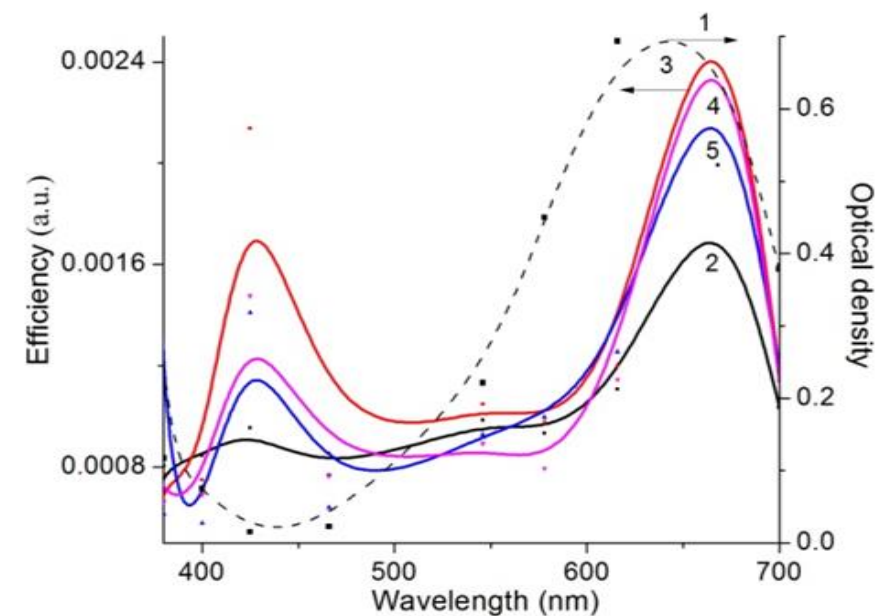

Fig. 3 The dependence of spectral sensitivity of solar cells sensitized by PD 1 (a) and PD 2 (b) via concentrations of $\mathrm{Ag} @ \mathrm{TiO}_{2} \mathrm{NPs}$, wt $\%: 2-0 ; 3-0.5 ; 4-1 ; 5-2$. Curve 1 - normalized absorption spectra of $\mathrm{PD}$ on the $\mathrm{TiO}_{2}$. 
Table 3 Photovoltaic parameters of DSSC based on PDs at various concentrations of Ag@ $\mathrm{TiO}_{2} \mathrm{NPs}_{\text {. }}$

\begin{tabular}{|c|c|c|c|c|}
\hline The concentration of $\mathrm{NPs}^{\mathrm{TiO}}{ }_{2} @ \mathrm{Ag}$, wt\% & $J_{s c}, \mathrm{~mA} / \mathrm{cm}^{2}$ & $V_{o c}, \mathrm{mV}$ & $F F$ & $\eta, \%$ \\
\hline \multicolumn{5}{|l|}{ PD 1} \\
\hline 0 & 0.11 & 375 & 0.15 & 0.06 \\
\hline 0.5 & 0.18 & 416 & 0.20 & 0.15 \\
\hline 1.0 & 0.11 & 375 & 0.16 & 0.07 \\
\hline 2.0 & 0.11 & 304 & 0.15 & 0.05 \\
\hline \multicolumn{5}{|l|}{ PD 2} \\
\hline 0 & 3.56 & 350 & 0.14 & 1.74 \\
\hline 0.5 & 3.94 & 354 & 0.15 & 2.09 \\
\hline 1.0 & 3.30 & 349 & 0.15 & 1.72 \\
\hline 2.0 & 3.00 & 349 & 0.14 & 1.47 \\
\hline
\end{tabular}

A solar cell with PD 1 is more sensitive to times in the presence of plasmon NPs. It leads to an increase photoirradiation in the wavelength range from 600 to $700 \mathrm{~nm}$ (Fig. 3a). In this case, the maximum spectral sensitivity exhibits at $660-670 \mathrm{~nm}$. Comparing the obtained curve with the absorption spectrum of PD 1 on the $\mathrm{TiO}_{2}$ surface, it was found that they coincide in shape.

An increase in the spectral sensitivity of the solar cell was noticed with addition of $\mathrm{Ag} @ \mathrm{TiO}_{2} \mathrm{NPs}$ to the bulk of a $\mathrm{TiO}_{2}$ film. At the same time, a band in the region of $400-450 \mathrm{~nm}$ was detected, which was absent in the spectra of PD 1 without silver NPs. The maximum of this short-wavelength band was registered at $420 \mathrm{~nm}$, which corresponds to the absorption band of plasmon Ag NPs. Similar data were obtained for semiconductor films sensitized with functionalized PD 2 (Fig. 3b, Table 4).

Table 4 Spectral sensitivity of DSSC based on PDs in the absence and presence of $\mathrm{Ag} @ \mathrm{TiO}_{2}$ NPs.

\begin{tabular}{|c|c|c|}
\hline \multirow[t]{2}{*}{ Sample } & \multicolumn{2}{|c|}{ Spectral sensitivity, a.u. $\times 10^{-4}$} \\
\hline & $420 \mathrm{~nm}$ & $670 \mathrm{~nm}$ \\
\hline $\mathrm{PD} \mathbf{1} / \mathrm{TiO}_{2}$ & 9.5 & 20.0 \\
\hline $\begin{array}{c}\mathrm{PD} 1 / \mathrm{TiO}_{2}+\mathrm{Ag} @ \mathrm{TiO}_{2}, 0.5 \\
\text { wt } \%\end{array}$ & 20.0 & 26.0 \\
\hline $\mathrm{PD} 2 / \mathrm{TiO}_{2}$ & 7.9 & 19.9 \\
\hline $\begin{array}{c}\mathrm{PD} 2 / \mathrm{TiO}_{2}+\mathrm{Ag} @ \mathrm{TiO}_{2}, 0.5 \\
w \mathrm{t} \%\end{array}$ & 21.0 & 30.1 \\
\hline
\end{tabular}

It should be noted that the spectral sensitivity, as well as the efficiency values at various wavelengths, is about $15 \%$ higher for PD 2 than for PD 1. This could be the result of a larger number of PD 2 molecules on the $\mathrm{TiO}_{2}$ surface due to the anchor groups in the dye molecule. Since the dyes absorb light in close spectral ranges, the spectral sensitivity curves for PD 1 and 2 are similar.

Moreover, the growth in the efficiency of DSSC with the dyes 1 and 2 is the result of an increase in the charge-transport characteristics of $\mathrm{TiO}_{2}$ films with the addition of "core@shell" plasmon nanostructures (Fig. 4, Table 5).

Under the plasmon effect of $\mathrm{Ag} @ \mathrm{TiO}_{2} \mathrm{NPs}$, the charge transfer resistance $R_{k}$ associated with the recombination of an electron and a hole was decreased significantly. Parameter $R_{k}$ was decreased by 8.2 times for PD 1 , for PD 2 - by 22.4 in the charge-transport characteristics of semiconductor films, which can be expressed in the growth of charge carriers reaching the counter electrode. This is also evidenced by the growth of $\tau_{\text {eff. }}$. Due to this the concentration of charge carriers grows and results in the deactivation of traps. This increases the part of photoelectrons reaching the counter electrode as it was shown in Refs. ${ }^{[11]}$ It is possible that there are other factors that will be the subject of subsequent studies.

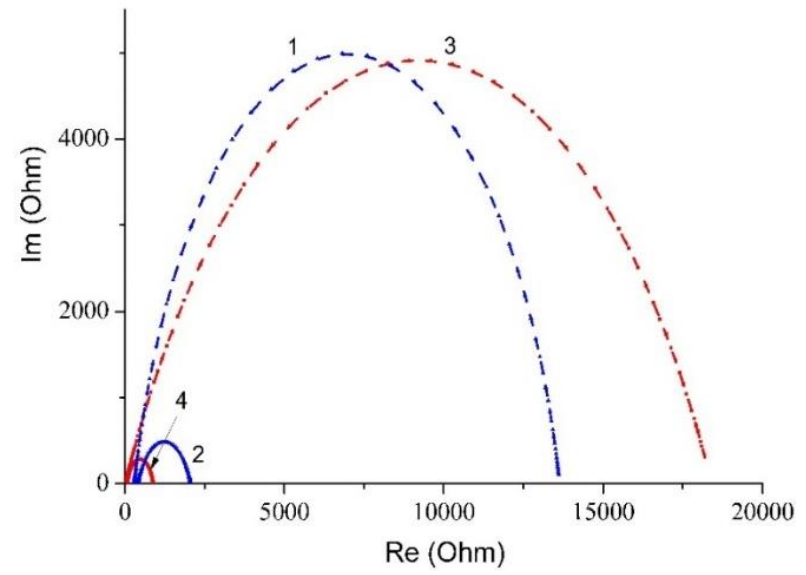

Fig. 4 Impedance spectra of solar cells, sensitized by PDs $1(1,2)$ and $2(3,4)$ in the presence $(2,4)$ and without $(1,3)$ of $\mathrm{Ag} @ \mathrm{TiO}_{2}$ NPs

Table 5 Electrotransport parameters of solar cells sensitized by PDs.

\begin{tabular}{|c|c|c|c|}
\hline Sample & $R_{k}, \mathrm{Ohm}$ & $R_{w}, \mathrm{Ohm}$ & $\tau_{\text {eff }}, \mathrm{ms}$ \\
\hline $\mathrm{PD} \mathbf{1} / \mathrm{TiO}_{2}$ & 13346 & 294.2 & 0.37 \\
\hline $\begin{array}{l}\mathrm{PD} \quad 1 / \mathrm{TiO}_{2}+\mathrm{Ag} @ \mathrm{TiO}_{2}, \\
0.5 \mathrm{wt} \%\end{array}$ & 1635 & 419.0 & 2.68 \\
\hline $\mathrm{PD} 2 / \mathrm{TiO}_{2}$ & 18392 & 11.4 & 0.10 \\
\hline $\begin{array}{l}\mathrm{PD} \quad 2 / \mathrm{TiO}_{2}+\mathrm{Ag} @ \mathrm{TiO}_{2}, \\
0.5 \mathrm{wt} \%\end{array}$ & 821 & 66.0 & 1.93 \\
\hline
\end{tabular}

\section{Conclusions}

The absorption and fluorescence bands of the studied PDs are located practically in the same spectral range of $500-800$ $\mathrm{nm}$ with the maxima at $640-650 \mathrm{~nm}$ for absorption and 655 - $660 \mathrm{~nm}$ for fluorescence. A similar shape of the dyes 
spectra due to the fact that they have almost the same chromophore.

During the adsorption of PDs molecules on the surface of $\mathrm{TiO}_{2}$, not only was a red shift $(\sim 10 \mathrm{~nm})$ and noticeable broadening of the absorption bands were observed. Along with this, there is also a quenching of fluorescence and a decreasing in the lifetime of the excited state of PDs 1 and 2 . Moreover, the efficiency of electron transfer to a semiconductor is much greater for a dye with functional groups. Thus, for PD 2, $\tau_{f l}$ on the $\mathrm{TiO}_{2}$ surface decreased by 3 times in comparison with $\tau_{f l}$ in solution. Whereas for PD $1 \tau_{f l}$ was decreased by 2.75 times under the same conditions. This can be explained by the presence of anchor sulfonate groups in the structure of dye 2. Those molecules are in closer contact with titanium dioxide nanoparticles that results in the growth in the number of electrons injected from $\mathrm{PD}$ to $\mathrm{TiO}_{2}$.

In the presence of $\mathrm{Ag} @ \mathrm{TiO}_{2} \mathrm{NPs}_{\text {at }}$ a concentration of 0.5 $\mathrm{wt} \%$, a plasmon-enhanced fluorescence of dyes was observed in the $\mathrm{TiO}_{2}$ film. The growth on $60-90 \%$ in the fluorescence intensity was observed. Moreover, for functionalized molecules, this effect is greater. It is likely that the observed increase in the intensity of the dye's fluorescence is associated with an increase in the radiative rate of dye molecules from $S_{1}$ to $S_{0}$ state. In this case, the excitation rate of molecules remains almost unchanged, because the optical density of the molecules increased slightly (on $3-5 \%$ ). Consequently, the increase in fluorescence intensity can be associated with an increase in the rate constant of the radiation decay of dye molecules due to the process of reverse energy transfer from $\mathrm{Ag} @ \mathrm{TiO}_{2} \mathrm{NPs}$ to the dye molecule, which is confirmed by the data on the value of $\tau_{f l}$ of PDs. In particular, in the presence of Ag NPs, the $\tau_{f l}$ of PD 1 increased 1.6 times, for PD 2 - by $\sim 1.2$ times. At the same time, weakening in the nonradiative deactivation of the $S_{1}$ state also possible, however, this process makes the least contribution.

Comparing the influence of functional groups in the structure of the dye on the efficiency of generation of charge carriers in the solar cell, it can be noted that the efficiency of DSSC with PD $2(1.74 \%)$ is higher than for PD $1(0.06 \%)$. Taking into account that the amount of loaded dye for all cells was the same, we can state that the presence of sulfonate groups in the dye molecule contributes to an increase in the efficiency of the solar cells due to closer contact with semiconductor particles.

An increase in the efficiency of solar cells sensitized by PDs by 2 and 1.2 times for PD 1 and 2, correspondingly, in the presence of plasmon nanostructures can be the result of an increased light harvesting of cells in wavelength range of $600-700 \mathrm{~nm}$ and its expansion in the region of short wavelengths $(400-450 \mathrm{~nm})$. In this case, plasmon enhancement of fluorescence and sensitization of the semiconductor proceed more efficiently for functionalized dyes. Moreover, the growth in the efficiency of DSSC with the dyes 1 and 2 is the result of an increase in the charge-transport characteristics of $\mathrm{TiO}_{2}$ films with the addition of "core@shell” plasmon nanostructures. The charge transport resistance decreased by 8.2 times for dye 1 and by 22.4 times for dye 2. This leads to the growth the part of photoelectrons reaching the counter electrode. This is also evidenced by an increase in the lifetime of nonequilibrium charge carriers in $\mathrm{TiO}_{2}$ films with $\mathrm{Ag} / \mathrm{TiO}_{2} \mathrm{NPs}$ by 7 and 19 times for PDs 1 and 2, respectively.

\section{Acknowledgements}

This work was supported by the research grants funded by the Ministry of Education and Science of the Republic of Kazakhstan (BR05236691) and Nazarbayev University FGRG grant (SEDS2020 016). This work was edited by Marat Nuraje (ERMHS).

\section{Availability of data and material.}

Data available within the article or its supplementary materials

\section{Supporting information}

Not applicable

\section{Conflict of interest}

There are no conflicts to declare.

\section{References}

[1] (a) M. K.Nazeeruddin, P. Péchy, T. Renouard, S M.Zakeeruddin, R. Humphry-Baker, P. Comte, P. Liska, L. Cevey, E. Costa, V. Shklover, L. Spiccia, G. B. Deacon, C. A. Bignozzi, M. Grätzel, J. the American Chem. Soc., 2001, 123, 1613-1624, doi: 10.1021/ja003299u; (b) S. Ito, T. N. Murakami, P. Comte, P. Liska, C. Grätzel, M. K. Nazeeruddin, M. Grätzel, Thin Solid Films, 2008, 516, 4613-4619, doi: 10.1016/j.tsf.2007.05.090; (c) M. Grätzel, J. Photochem. Photobiol., A, 2004, 164, 3-14, doi: 10.1016/j.jphotochem.2004.02.023.

[2] (a) A. Yella, H. W. Lee, H. N. Tsao, C. Yi, A. K. Chandiran, M. K. Nazeeruddin, E. W. Diau, C. Y. Yeh, S. M. Zakeeruddin, M. Grätzel, Science, 2011, 334, 629, doi: 10.1126/science.1209688; (b) T. Higashino, H. Imahori, Dalton Trans., 2015, 44, 448-463,doi: 10.1039/C4DT02756F.

[3] K. Kakiage, Y. Aoyama, T. Yano, K. Oya, J. Fujisawa, M. Hanaya, Chem. Commun., 2015, 51, 15894-15897, doi: 10.1039/C5CC06759F.

[4] L. Liu, Y. Kan, K. Gao, J. Wang, M. Zhao, H. Chen, C. Zhao, T. Jiu, A. K. Y. Jen, Y. Li, Adv. Mater, 2020, 32, 1907604, doi: 10.1002/adma.201907604. 
[5] (a) N. Ibrayev, E. Seliverstova, A. Aimukhanov, T. Serikov,. Mol. Cryst. Liq. Cryst., 2014, 589, 202-208, doi: 10.1080/15421406.2013.872827; (b) N. Ibrayev, E. Seliverstova, N. Nuraje, A. Ishchenko, Mater. Sci. Semicond. Process., 2015, 31, 358-362, doi: 10.1016/j.mssp.2014.12.006.

[6] (a) A. A. Ishchenko, Russ. Chem. Rev., 1991, 60, 865-884, doi: 10.1070/RC1991v060n08ABEH001116; (b) A. A. Ishchenko, Theor. Exp. Chem., 1998, 34, 191-210, doi: 10.1007/BF02523249.

[7] G. V. Bulavko, A. A. Ishchenko, Russ. Chem. Rev., 2014, 83, 575-599, doi: 10.1070/RC2014v083n07ABEH004417.

[8] A. Mishra, M K R Fischer, P. Bäuerle, Angew. Chem., Int. Ed., 2009, 48, 2474-2499, doi: 10.1002/anie.200804709.

[9] (a) K. Sharma, V. Sharma, S. S. Sharma, Nano. Res. Lett., 2018, 13, 381, doi: 10.1186/s11671-018-2760-6; (b) N. K. Ibrayev, E.V. Seliverstova, A. A. Ishchenko, M. A. Kudinova, J. Photochem. Photobiol. A, 2017, 346, 570-575, doi: 10.1016/j.jphotochem.2017.06.029.

[10] C. D. Geddes, J. R. Lakowicz, J. Fluoresc., 2002, 12, 121-129, doi: 10.1023/A:1016875709579.

[11] D. A. Afanasyev, N. K. Ibrayev, T. M. Serikov, A. K. Zeinidenov, Rus. J. Phys. Chem. A, 2016, 90, 833-837, doi: 10.1134/s0036024416040026.

[12] (a) F. Enrichi, A. Quandt, G.C. Righini, Renew. Sustain. Energy Rev., 2018, 82, 2433-2439, doi: 10.1016/j.rser.2017.08.094; (b) J. Wang, S. Jia, Y. Cao, W. Wang, P. Yu, Nano. Res. Lett., 2018, 13, 211, doi: 10.1186/s11671-018-2620-4; (c) E. V. Seliverstova, N. K. Ibrayev, A. Z. Zhumabekov, Opt. Spectrosc., 2020, 128, 1449, doi: 10.1134/S0030400X20090192.

[13] (a) P. Anger, P. Bharadwaj, L. Novotny, Phys. Rev. Lett., 2006, 96, 113002, doi: 10.1103/physrevlett.96.113002; (b) N. Ibrayev, E. Seliverstova, N. Zhumabay, Temirbayeva, J. Lumin. 2019, 214, 116594, doi: 10.1016/j.jlumin.2019.116594; (c) X. M. Hua, J. I. Gersten, A. Nitzan, J. Chem. Phys. 1985, 83, 3650-3659. doi: 10.1063/1.449120.

[14] M. Yang, P. Moroz, Z. Jin, D. S. Budkina, N. Sundrani, D. Porotnikov, J. Cassidy, Y. Sugiyama, A. N. Tarnovsky, H. Mattoussi, M. Zamkov, J. Am. Chem. Soc., 2019, 141, 11286-11297, doi: 10.1021/jacs.9b04697.

[15] G. Klimusheva, S. Bugaychuk, Y. Garbovskiy, O. Kolesnyk, T. Mirnaya, A. Ishchenko, Opt. Lett., 2006, 31, 235-237, doi: 10.1364/ol.31.000235.

[16] (a) J. Bisquert, G. Garcia-Belmonte, F. Fabregat-Santiago, P. R. Bueno, J. Electroanal. Chem., 1999, 475, 152-163, doi: 10.1016/s0022-0728(99)00346-0; (b) R. Kern, R. Sastrawan, J. Ferber, R. Stangl, J. Luther, Electrochim. Acta, 2002, 47, doi: 10.1016/s0013-4686(02)00444-9.

[17] (a) H. Lu, J. N. Prieskorn, J. T. Hupp, J. Am. Chem. Soc.,
1993, 115, 4927-4928, doi: 10.1021/ja00064a079; (b) R. Huber, S. Spörlein, J. S. Moser, M. Grätzel, J. Wachtveitl, J. Phys. Chem. B, 2000, 104, 8995-9003, doi: 10.1021/jp9944381.

[18] N. Ibrayev, A. Ishchenko, D. Afanasyev, N. Zhumabay, Appl. Phys. B, 2019, 125, 182, doi: 10.1007/s00340-019-7292-y. [19] A. S. Tatikolov, N. A. Derevyanko, A. A. Ishchenko, I. Baraldi, M. Caselli, F. Momicchioli, G. Ponterini, Ber. Bunsenges. Phys. Chem, 1995, 99, 763-769, doi: 10.1002/bbpc. 19950990512 .

[20] D. A. Afanasyev, N. K. Ibrayev, G. S. Omarova, A.V. Kulinich, A. A. Ishchenko, Opt. Spectrosc., 2020, 128, 61-65, doi: 10.1134/s0030400x20010026.

\section{Author information}

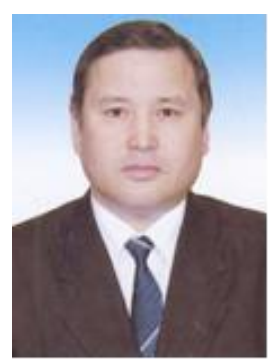

Niyazbek Ibrayev received degree of Candidate of Physical and Mathematical Sciences in 1984 from Lomonosov Moscow State University, Russia. The degree of Doctor of Physical and Mathematical Sciences he obtained in the 1998 in the Institute of Physics and Technology, Kazakhstan. At present N. Ibrayev is the Professor at the Department of Physics and nanotechnologies of Buketov Karaganda University, Karaganda, Kazakhstan. Niyazbek Ibrayev is the head of the Institute of Molecular Nanophotonics of Buketov Karaganda University. Research interests: condensed matter physics, nanophotonics, nanoplasmonics, solar energy.

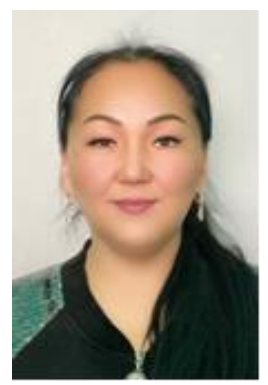

Gulden Omarova is the $3^{\text {rd }}$ year $P h D$ student under the supervision of Prof. Ibrayev N. and Prof. N. Nuraje at the Institute of Molecular Nanophotonics of Buketov Karaganda University, Karaganda, Kazakhstan. She obtained master's degree in 2005 from abovementioned University. Her current research focuses on studying of plasmon effect on photonics of polymethine dyes and its using in the photovoltaic and quantum electronics.

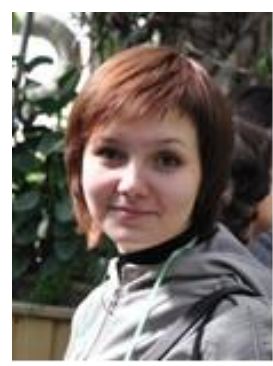

Evgeniya Seliverstova obtained PhD degree in 2014 from Buketov Karaganda University, Karaganda, Kazakhstan. She is currently working as senior researcher in the Institute of Molecular Nanophotonics of Buketov Karaganda University. Her research interests include 
the dynamics of electronic excitations in organic nanostructures, photonics, plasmonics and carbon nanostructures.

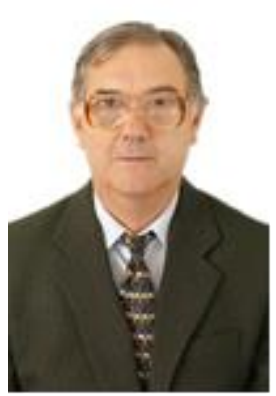

Alexander Ishchenko is the Doctor of Chemical Sciences, PhD, Professor of Organic Chemistry. He is the Corresponding member of the National Academy of Sciences of Ukraine. Currently he is the head of the department of Color and Structure of Organic Compounds at the Institute of Organic Chemistry, National Academy of Sciences of Ukraine. Additional information could be found via link http://ioch.kiev.ua/institute/research-departments/colour-and -structure-of-organic-compounds-department.

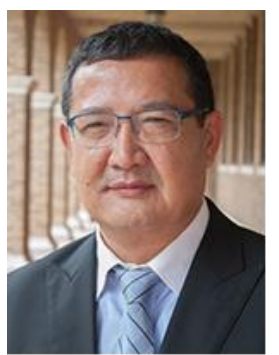

Nurxat Nuraje received his PhD degree from CUNY in 2008. He was a postdoctoral associate in the Department of Materials Science and Engineering at MIT from 2008 to 2013 and a research scientist at MIT from 2013 to 2015. Then, he joined the chemical engineering department of Texas Tech University as an Assistant Professor starting from January of 2015. On August 26th of 2019, Dr. Nuraje started associate professorship position in the department of chemical and materials engineering of Nazarbayev University (NU) and is leading a NU Research Lab-Advanced Functional Materials \& Device. During his PhD study, he was awarded the "Graduate Student Silver Medal" by the Materials Research Society (MRS) and the "Rose Kfar Rose" award by CUNY. In 2015, due to his outstanding researches in nanoscience, he was selected as the winner of the "Joseph Wang Award" by Cognizure organization. Dr. Nuraje has been awarded US Air Force Summer Faculty Fellowship for the years of 2017, 2018 and 2019, and was named one of the 2018's RSC emerging investigators by Journal of Materials Chemistry A. In 2017, for his excellent performance in teaching, Dr. Nuraje was recognized as the most influential faculty member by college of engineering of Texas Tech University. So far, he has published more than 70 peer reviewed journal articles and 7 book chapters. As a primary editor, he published the RSC book- "Green Photoactive Nanomaterials: Sustainable Energy and Environmental Remediation". At present, he serves as Editorial board members of three journals which are Materials Science in Semiconductor Processing (Elsevier), Journal of Experimental Science (Francis \&
Taylor), and Advanced Composites \& Hybrid Materials (Springer). As a guest editor, he organized two special issues. One is "Photoactive Nanomaterials" for the Journal -Nanomaterials. The second one is "Functional Green Nanomaterials" for the journal- Nanoscience and Nanotechnology-Asia (Bentham Science). He has served as chair/co-chair for four technical sessions in AICHE national meeting, and grant reviewers for US NSF, ACS PRF, National Center of Science and Technology Evaluation (Kazakhstan), and National Science Center of Poland. Dr. Nuraje's research interests are primarily in nanomaterials and polymeric materials. Specifically, his goal is to explore the physical and chemical properties of new functional materials and understand their "bottom-up" assembly and formation into hierarchical structures with the goals of discovering new fundamentals and bringing about breakthroughs in solar energy conversion, environmental remediation, and oil recovery.

Publisher's Note: Engineered Science Publisher remains neutral with regard to jurisdictional claims in published maps and institutional affiliations. 